\title{
Aquifer Area Investigation Using Resistivity Method in Cikopomayak, West Java, Indonesia
}

\author{
Investigasi Area Akuifer Menggunakan Metoda Resistivitas di Cikopomayak, Jawa Barat, Indonesia
}

\author{
Sihotang J.W. ${ }^{1 *}$, Munte D.B.T. ${ }^{1}$, Osvaldus R. ${ }^{1}$, Priono N. ${ }^{1}$ dan Mohamad F. ${ }^{2}$ \\ ${ }^{1}$ Fakultas Teknik Geologi, Universitas Padjadjaran, Jatinangor, Indonesia \\ ${ }^{2}$ Laboratorium Geofisika, Universitas Padjadjaran, Jatinangor, Indonesia \\ *Email: josua16005@mail.unpad.ac.id
}

\begin{abstract}
Administratively, the research area is located in around Cikopomayak Village, Jasinga, Bogor, West Java, Indonesia. Based on the Hydrogeological and Groundwater Basin Map, this research area was classified to non-potential groundwater basin. In addition, when the summer comes, the lack of water will be happened around the area. Consequently, the water reserve wasn't enough to fulfill the necessity of freshwater. Thus, the research about identifying aquifer location was needed. This research aims to determine the depth and thickness of aquifer for the alternative ways to overcome the problem, particularly, for the Cikopomayak Village. The research used the geophysical method by modeling the several data such as Geoelectric 1-D to know the aquifer location based on the section of medium resistivity value. Then, the geoelectric data was correlated to the borehole drilling data that is Gamma Ray (GR) Log, Spontaneous Potential (SP) Log, Resistivity Log, and the cutting data. Commonly, the most suitable lithology for an aquifer is sandstone because of its good characteristic of permeability and porosity. Logging data result will show the small value of GR log, SP Log leaning to the right, and low-value resistivity for indicating the aquifer zone. Based on geoelectric data, the research zone has 3 groups of resistivity value and lithology that are shaly claystone and siltstone with low-value resistivity $(0-50$ S.m), sandy claystone, medium sandstone, and coarse sandstone with medium value resistivity (50 - 150 S.m), fine sandstone, sandy claystone, and andesite with high-value resis-

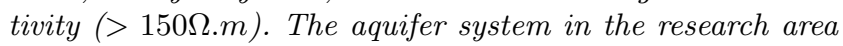
was classified into 3 groups that are aquifer, aquitard, and aquiqlud.
\end{abstract}

Keywords: Aquifer potential, Resistivity, Bogor

Abstrak: Secara administratif, daerah penelitian termasuk ke dalam wilayah Desa Cikopomayak dan sekitarnya, Kecamatan Jasinga, Bogor. Berdasarkan peta Hidrogeologi dan peta Cekungan Air Tanah (CAT), daerah penelitian ini tergolong kedalam cekungan air tanah tidak potensial. Hal ini didukung, ketika musim kemarau, ketersediaan air tanah di daerah ini berkurang sehingga tidak dapat memenuhi kebutuhan air bersih warga. Oleh karena itu, penelitian mengenai keberadaan air tanah (akuifer) di Kecamatan Jasinga perlu dilakukan. Penelitian ini bertujuan untuk mengetahui lokasi kedalaman serta ketebalan akuifer dangkal sebagai alternatif dalam pemenuhan kebutuhan air bersih, khususnya bagi warga Desa Cikopomayak. Penelitian ini dilakukan dengan pemodelan dari data geolistrik 1-D untuk mengetahui lokasi akuifer berdasarkan data penampang resistivitas batuan yang bernilai menengah. Selanjutnya, pada daerah tersebut, dilakukan pemboran untuk mengetahui letak kedalaman akuifer berdasarkan data Gamma Ray (GR) Log, Spontaneous Potential (SP) Log, Resistivity Log, dan deskripsi cutting. Akuifer pada umumnya terdapat pada litologi batupasir karena memiliki porositas dan permeabilitas yang baik. Hasil data logging akan menunjukkan nilai GR log yang kecil, SP Log yang condong ke kanan, dan nilai resistivity cenderung kecil sebagai indikasi zona akuifer. Berdasarkan data geolistrik 1-D, daerah penelitian digolongkan ke dalam tiga kelompok nilai tahanan jenis dan litologi, yaitu kelompok nilai tahanan jenis rendah $(0-50 \Omega . m)$ dengan litologi batulanau dan batulempung - serpih, menengah (50 - 150 $\Omega . m$ ) dengan litologi , batupasir sedang, batupasir kasar,

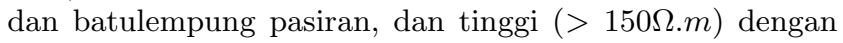
litologi batulempung pasiran dan batupasir halus. Lokasi akuifer dibuktikan dari korelasi data geolistrik 1-D dengan data sumur pemboran yang menunjukkan adanya lapisan batupasir sedang - batupasir kasar pada kedalaman $19-27$ m. Sistem akuifer di daerah penelitian dibagi menjadi tiga bagian yaitu akuifer, akuiklud, dan akuitard.

Kata kunci:Potensi akuifer, Resistivitas, Bogor

\section{PENDAHULUAN}

Secara geografis, daerah Cikopomayak terletak pada $106^{\circ}$ 26' 32" BT sampai $106^{\circ} 28^{\prime} 53^{\prime \prime}$ BT dan $-6^{\circ} 25^{\prime} 58^{\prime \prime}$ LS sampai $-6^{\circ} 28^{\prime}$ " " LS. Daerah ini merupakan bagian dari Kecamatan Jasinga, Kabupaten Bogor, Provinsi Jawa Barat yang tergolong ke dalam wilayah Cekungan Air Tanah (CAT) Bogor. Seiring dengan pertumbuhan jumlah penduduk dan perkembangan infrastruktur, kebutuhan akan air bersih bagi warga di sekitar Desa Cikopomayak kian meningkat. Hal ini membuat sebagian warga mencari alternatif tambahan supplai air dari air sungai dengan menempuh jarak yangr relatif jauh dan kualitas air yang kurang terjamin akibat dari kontaminasi limbah rumah tangga. Dampak jangka panjang dari kejadian ini yaitu dapat menyebabkan berba- 


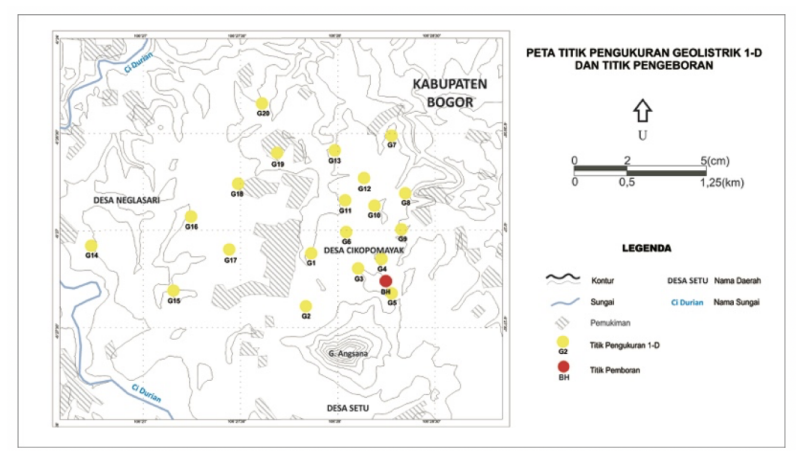

Gambar 1. Peta geologi regional daerah Bogor, dan daerah penelitian ditandai dengan kotak berwarna merah (dimodifikasi dari E.Rusmana, dkk., 1991)

gai permasalahan sosial terjadi seperti munculnya berbagai penyakit di masyarakat.

Akuifer merupakan lapisan pembawa air yang terdapat di dalam tanah. Berdasarkan pengertiannya, akuifer yang baik memiliki sifat yang porous dan permeable agar dapat menyimpan dan meloloskan air dengan mempertimbangkan saturasi airnya. Umumnya, akuifer dapat berupa batupasir karena sifatnya yang porous dan juga permeable. Hal ini tidak sebanding dengan kondisi geologi di daerah Cikopomayak yang didominasi oleh batulempung dan batulanau yang kurang porous dan cenderung impermeable. Oleh sebab itu, penting dilakukannya analisis distribusi akuifer untuk mengetahui persebaran dari air tanah beserta letak kedalamannya. Penelitian ini bertujuan untuk memodelkan geometri akuifer di sekitar Kecamatan Jasinga, CAT Bogor.

\section{DATA DAN METODOLOGI}

Pengukuran geolistrik 1-D dilakukan pada dua puluh titik tersebar di Kecamatan Jasinga (Gambar 1). Setelah melakukan pengukuran, dilakukan pemodelan nilai resistivitas pada kedalaman $25 \mathrm{~m}, 50 \mathrm{~m}, 75 \mathrm{~m}, 100 \mathrm{~m}, 125 \mathrm{~m}, 150$ $\mathrm{m}$ untuk mengetahui presebaran nilai resistivitas secara lateral.

Nilai resistivitas dari hasil pengukuran geolsitrik 1-D dibagi menjadi 3 bagian yaitu resistivitas rendah (0-50) $\Omega . m$, resistivitas menengah (50-150) $\Omega . \mathrm{m}$, dan resistivitas tinggi

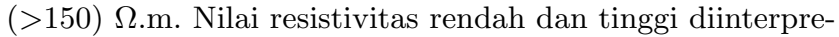
tasikan sebagai batuan dengan porositas dan permeabilitas yang kurang baik untuk menjadi akuifer. Nilai resistivitas sedang diinterpretasikan sebagai zona memungkinkan sebagai akuifer berdasarkan nilai literature resistivitas batupasir dan air tanah.

Penelitian ini menggunakan gabungan dari beberapa metode geofisika yaitu Geolistrik 1-D, Well Logging Method, dan data cutting pemboran. Geolistrik merupakan salah satu metode geofisika aktif yang bekerja dengan menginjeksikan arus listrik ke dalam bumi untuk mengetahui persebaran nilai resistivitas setiap batuan. Metode geolistrik dilakukan sebagai tahapan awal dalam eksplorasi air tanah. Setelah eksplorasi awal, dilakukan metode eksplorasi Well Logging yang lebih mendetail dengan cakupan luas yang lebih spesifik. Metode Well Logging dapat merekam data fisik batuan dengan menggunakan beberapa well devices seperti, Spontaneous Potential Log, Gamma-Ray Log, dan Resistivity Log.

Beberapa tahapan dalam penelitian ini yaitu:

(i) Eksplorasi awal menggunakan metode geolistrik 1-D. Geolistrik 1-D dilakukan di 20 titik injeksi. Dari hasil Geolistrik 1-D dengan konfigurasi Schlumberger, persebaran nilai resistivitas dapat diketahui pada 1 titik wilayah dengan kedalaman mencapai 150 meter. Setiap nilai resistivias per kedalaman $10 \mathrm{~m}, 25 \mathrm{~m}, 50 \mathrm{~m}, 75 \mathrm{~m}, 100 \mathrm{~m}, 125 \mathrm{~m}$, dan $150 \mathrm{~m}$ dimodelkan untuk mengetahui persebaran nilai resistivitas secara lateral. Daerah dengan nilai resistivitas menengah (100-150 ohm meter) diinterpretasi sebagai daerah berpotensi akuifer.

(ii) Eksplorasi lanjut menggunakan metode Well Logging dilakukan pada sumur pemboran di daerah berpotensi akuifer berdasarkan hasil analisis geolistrik. Metode ini menggunakan 3 perangkat Well Logging yaitu Spontaneous Potential Log, Gamma-Ray Log, dan Resistivity Log. Batuan yang porous dan permeable akan menunjukkan nilai log SP yang condong ke kiri, Gamma-Ray rendah, dan Resistivitas yang juga rendah. Hal ini dikarenakan pada batupasir memiliki sifat yang porous, permeable, serta kandungan radioaktif yang rendah membuat fluida dapat masuk ke ruang antar butir. Hal ini memungkinkan air untuk masuk ke ruang antar butir yang dapat dilihat berdasarkan nilai resistivitas pemboran.

(iii) Identifikasi batuan terhadap kedalaman dari hasil pengeboran dengan menghubungkan rekaman data Well Logging dan data cutting pemboran.

\subsection{Tatanan Geologi}

Daerah Jasinga terletak di sekitar tepi laut Jawa yang membentang kurang lebih $40 \mathrm{~km}$ dari Serang hingga ke Cirebon sehingga dapat digolongkan ke dalam fisiografi zona Jakarta (Gambar 2). Sebagian besar wilayah ini ditutupi oleh endapan alluvial yang terbawa oleh arus sungai yang bermuara di laut Jawa seperti Ci Punagara, Ci Tarum, Ci Sanggarung, Ci Manuk, Ci Keruh dan Ci Asem. Sebagian dari zona ini juga ditutupi oleh endapan lahar dari Gunung Gede, Gunung Pangrango, dan Gunung Tangkuban Perahu berupa endapan kipas alluvial vulkanik khususnya perbatasan dengan zona Bandung (Bemmelen, 1949).

Mengacu pada Peta Geologi Regional Lembar Serang, daerah penelitian ini tersusun atas batuan sedimen formasi Bojongmanik yang berumur Miosen hingga Tersier berdasarkan skala waktu Geologi (Rusmana, dkk., 1991). Formasi ini dibagi kedalam 3 anggota yang berbeda, yaitu (Herlambang \& Haryoto, 2005):

(i) Anggota lapisan terbawah: tersusun oleh batugamping dengan perselingan antara batulempung dan batupasir. Batuan ini memiliki retakan dan lubang hasil dari pelarutan, bersifat keras dan memiliki permeabilitas rendah

(ii) Anggota kedua: tersusun oleh batupasir kuarsa, batulempung, dan tuf yang mengandung fosil moluska. Batuan ini bersifat impermeabel.

(iii) Anggota ketiga: tersusun oleh batupasir lempungan, batupasir tuf kasar, dengan perselingan batugamping. Umumnya, batuan ini memiliki permeabilitas rendah. 


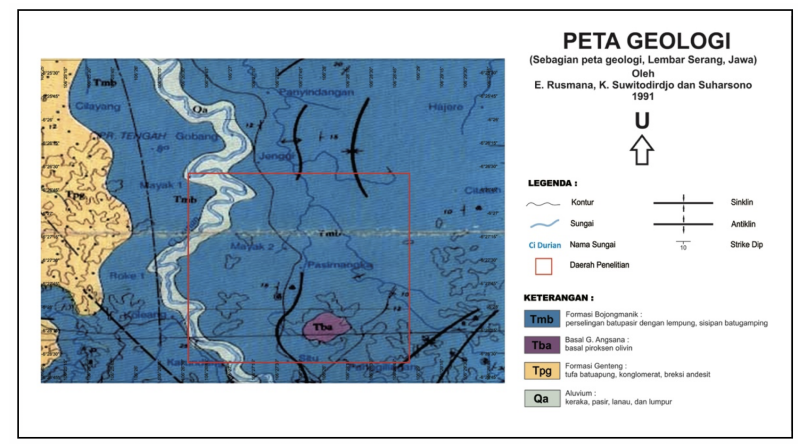

Gambar 2. Peta geologi regional daerah Bogor, dan daerah penelitian ditandai dengan kotak berwarna merah (dimodifikasi dari Rusmana, dkk., 1991)

\subsection{Kondisi Hidrogeologi}

Berdasarkan Peta Hidrogeologi Kabupaten Bogor dan Peta CAT Lembar Jawa Barat, wilayah penelitian digolongkan ke dalam jenis akuifer langka atau tidak berarti dan akuifer tidak potensial. Kecamatan Jasinga memiliki rata-rata curah hujan tahunan sebesar 1500-2000 mm (IWACO \& WASECO, 1990). Batas hidrogeologi CAT Bogor yang dikontrol oleh kondisi geologis dan/atau kondisi hidraulik air tanah, adalah sebagai berikut (Rakhman, M. A., 2013),

- Di bagian Utara terdapat batas tidak ada aliran eksternal yang berada di daerah antara Parung-Depok

- Di bagian Selatan dibatasi oleh punggungan G. Kendang, G. Perbakti, G Salak, dan G. Gede- Pangrango yang merupakan batas pemisah air tanah yang berimpit dengan batas pemisah air permukaan.

- Di bagian Timur dibatasi oleh batuan kedap air berupa batu lempung dan napal berumur Tersier yang merupakan batas tidak ada aliran eksternal, selain itu punggungan G. Kencana merupakan batas pemisah air tanah yang berimpit dengan batas utama air permukaan.

- Di bagian Barat dibatasi oleh batuan kedap air yaitu batu lempung dan napal berumur Tersier yang merupakan batas tidak ada aliran eksternal.

- Batas vertikal bagian bawah atau alas CAT Bogor adalah batas tanpa aliran internal yang merupakan persentuhan antara akuifer utama dan batuan berumur tersier bersifat lempungan dan kedap air, yang menjadi penyusun formasi jatiluhur.

Data hidrogeologi menunjukkan di Cekungan Air Tanah daerah Bogor dijumpai dua sistem akuifer yakni sistem akuifer tidak tertekan dan sistem akuifer tertekan. Pada sistem akuifer tertekan, penyebarannya dikontrol oleh keadaan geologi setempat. Sistem akuifer ini terutama dibentuk oleh hasil endapan gunung api kuarter dari G. Salak dan G. Gede-Pangrango dengan litologi terutama terdiri dari pasir tufaan, batu pasir, dan breksi bersifat tufaan, sedangkan sisanya dibentuk oleh endapan sedimen Tersier. Berdasarkan litologi dan hidrolika menunjukan keberadaan sistem akuifer tidak tertekan yang berada di Cekungan Air Tanah Bogor berada di kedalaman kurang dari $30 \mathrm{~m}$ di bawah permukaan tanah, sedangkan akuifer tertekan berada pada kedalaman antara 30-180 $\mathrm{m}$ dibawah permukaan tanah.

\section{HASIL DAN DISKUSI}

Penelitian ini mendapatkan profil kontur isoresistivitas (Gambar 3). nilai resistivitas menengah terdapat secara dominan pada kedalaman $50 \mathrm{~m}, 75 \mathrm{~m}$, dan $100 \mathrm{~m}$. Pada kedalaman $25 \mathrm{~m}$ dan $125 \mathrm{~m}$ didominasi oleh nilai resistivitas rendah dan pada kedalaman $150 \mathrm{~m}$ didominasi oleh nilai resistivitas menengah-tinggi. Potensi akuifer dangkal diperkirakan terdapat pada sebelah tenggara nilai resistivitas batuan pada kedalaman sampai $50 \mathrm{~m}$.

Dari hasil pemodelan secara lateral per kedalaman dari nilai resistivitas batuan, dilakukan pemodelan penampang berarah Utara-Selatan dan Barat-Timur untuk mengetahui distribusi nilai resistivitas menengah. Pembuatan penampang dilakukan dengan mengkorelasikan data geolistrik 1-D pada titik pengukuran terpilih. Pemilihan titik pengukuran untuk dijadiakan penampang dipilih berdasarka arah dari perseberan batuan.

Berdasarkan penampang Utara-Selatan, nilai resistivitas menengah terdapat pada kedalaman 0-80 $\mathrm{m}$ di atas permukaan laut (dapl) dan 0-120 m di bawah permukaan laut $(\mathrm{dbpl})$. Berdasarkan penampang Barat-Timur, nilai resistivitas menengah terdapat pada kedalaman 0-40 m dapl dan bervariasi pada kedalaman 10-180 dbpl. Nilai penampang tersebut digunakan sebagai data eksplorasi awal dan pertimbangan lokasi pemboran untuk mengetahui letak akuifer secara lebih detail.

Lokasi pemboran berada diantara titik G4 dan G5 yang dipilih karena keberadaan nilai resistivitas menengah yang dominan (Gambar 4). Berdasarkan data geolistrik 1-D, daerah penelitian digolongkan ke dalam tiga kelompok nilai tahanan jenis dan litologi, yaitu kelompok nilai tahanan jenis rendah $(0-50 \Omega . m)$ dengan litologi batulanau dan batulempung - serpih, menengah $(50-150 \Omega . m)$ dengan litologi , batupasir sedang, batupasir kasar, dan batulempung pasiran, dan tinggi (¿150 $\Omega . m$ ) dengan litologi batulempung pasiran dan batupasir halus. Beberapa data hasil pemboran yaitu Well Logging Data Record dan deskripsi cutting. Berdasarkan data pemboran, sistem akuifer pada daerah penelitian dibagi menjadi 3 bagian, yaitu:

- Akuifer: Batupasir halus - kasar pada kedalaman 19-27 m, 78-83 m, 32-33 m, dan 124-133 m

- Akuitard: Batulempung pasiran - Batupasir halus pada kedalaman 35-42 m, 43-78 m, dan 133- $150 \mathrm{~m}$

- Akuiklud: Batulempung - Batulanau pada kedalaman 4-19 m, 27-32 m, 33-35 m, 42-43 m, dan 83-124 m

Dari hasil interpretasi data Well Logging, zona akuifer dapat ditemukan pada kedalaman 19-27 m. Pada lapisan ini, Gamma Ray memiliki nilai yang relatif rendah menunjukkan lapisan yang memiliki kandungan radioaktif rendah (bukan batulempung); SP Log memiliki nilai yang relative tinggi diluar dari baseline yang menunjukkan bukan lapisan batulempung; dan Resistivity Log memiliki nilai yang relatif tinggi menunjukkan lapisan porous dengan pengisi berupa fresh water.

Data Well Logging ini diperkuat oleh deskripsi data cutting yang menunjukkan bahwa lapisan batuan merupakan batupasir kasar secara dominan yang membuat sifat batuan semakin porous. Pada kedalaman 78-83 m dan 124-133 m, Lapisan batuan merupakan batupasir yang memungkinkan untuk dieksploitasi. Namun, nilai Resistivity Log yang ter- 


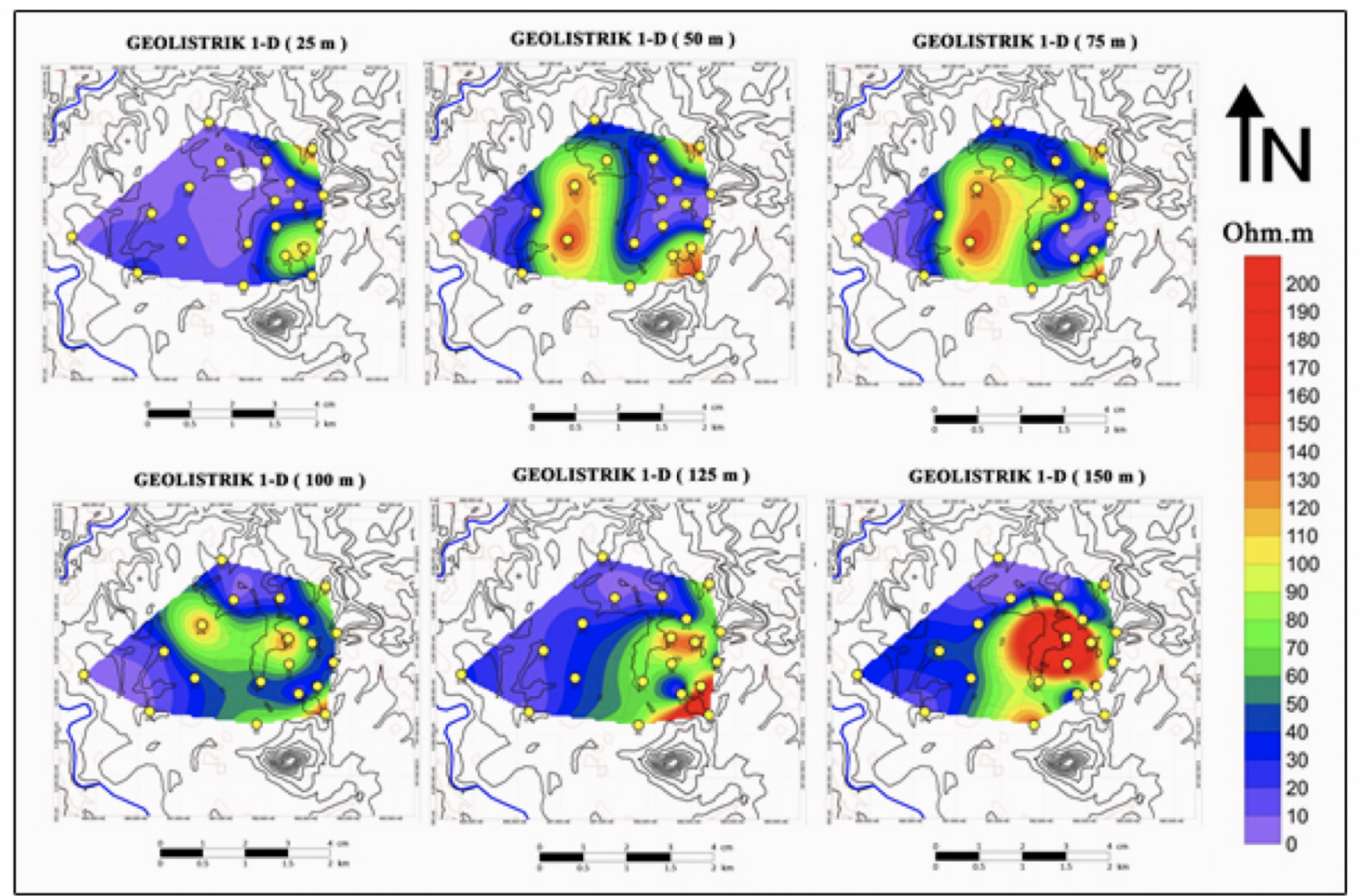

Gambar 3. Peta isoresistivitas batuan secara lateral berdasarkan kedalaman

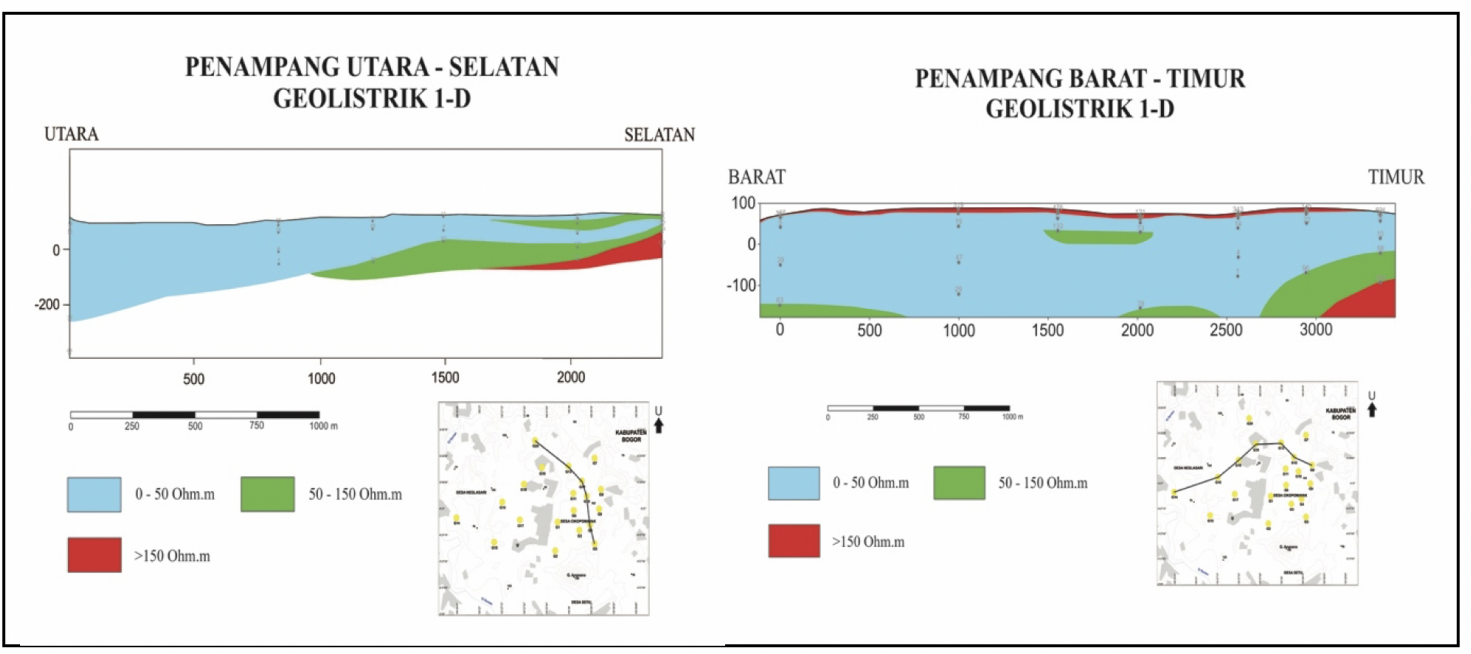

Gambar 4. Penampang hasil nilai resistivitas berarah Utara-Selatan dan Barat-Timur

lalu rendah menunjukkan bahwa fluida pengisi batuan ini bukan merupakan fresh water yang berbeda pada akuifer kedalaman 19-27 m.

\section{KESIMPULAN}

Berdasarkan peta Cekungan Air Tanah (CAT) Lembar Jawa Barat dan Peta Hidrogeologi Kabupaten Bogor, wilayah Cikopomayak digolongkan ke dalam jenis akuifer tidak potensial. Hal ini dipengaruhi oleh kondisi batuan di wilayah penelitian yang didominasi oleh Batulempung - Batulanau. Berdasarkan data pemboran, hanya terdapat 1 lapisan akuifer yang tergolong ke dalam fresh water pada kedalaman $19-27 \mathrm{~m}$.

Data pemboran didominasi oleh Batulempung - Batulanau - Batulempung pasiran yang kurang mendukung untuk dapat menjadi lapisan pembawa air (akuifer). Sistem akuifer di daerah penelitian dibagi menjadi 3 bagian, yaitu akuifer, akuiklud, dan akuitard. Dengan diketahuinya letak kedalaman akuifer, warga Desa Cikopomayak dan seki- 
tarnya dapat mengeksploitasi dan memanfaatkan nya sebaik mungkin untuk kepentingan bersama dengan tetap menjaga kualitas dari akuifer tersebut.

\section{DAFTAR PUSTAKA}

Bemmelen, R.W. Van., (1949) The Geology Indonesia. The Hague Martinus.

Herlambang, A., dan Haryoto, R.I., (2005) Pengelolaan Air Tanah dan Intrusi Air Laut. JAI, 1(2), pp. 3.

Rusmana, E., Suwitordidjo, K., dan Suharsono, 1991. Peta Geologi Lembar Serang, Jawa Skala 1:100.000.

Rakhman, M. A., 2013. Potensi Air Tanah di Cekungan Air Tanah Bogor Berdasarkan Metode Anlytic Hierarchy Process (AHP). Departemen Geografi, FMIPA UI. Depok. 